BIODIK: Jurnal IImiah Pendidikan Biologi
ISSN 2580-0922 (online), ISSN 2460-2612 (print)
Volume 7, Nomor 02, Tahun 2021, Hal. 97-109
Available online at:
https://online-journal.unja.ac.id/biodik

Research Article OPEN ACCESS

\title{
Analisis dan Rekonstruksi LKPD Berbasis Abad 21 Pada Praktikum Tulang
}

\author{
(Analysis and Reconstruction of LKPD Based on the 21st Century in Bone Practicum)
}

\author{
Gusni Nugraha As Syiba*, Bambang Supriatno, Sri Anggraeni \\ Program Studi Pendidikan Biologi, Fakultas Pendidikan Matematika dan IImu Pengetahuan Alam \\ Universitas Pendidikan Indonesia
}

Jl. Dr. Setiabudi No. 29, Bandung, Indonesia 40154

*Corresponding author : gusniassyiba@gmail.com

\begin{tabular}{|c|c|}
\hline Informasi Artikel & ABSTRACT \\
\hline $\begin{array}{l}\text { Submit: } 05-02-2021 \\
\text { Diterima: } 26 \text { - } 05-2021 \\
\text { Dipublikasikan: } 02-06-2021\end{array}$ & $\begin{array}{l}\text { Student Worksheets (LKPD) on Biology learning, especially bone material in the field, } \\
\text { are currently not optimal. This can be seen from the content of the LKPD which does } \\
\text { not cover all competencies as formulated in the curriculum. This study aims to } \\
\text { reconstruct LKPD on bone material. The research method is descriptive qualitative } \\
\text { using the ANCOR (Analysis-Try-Reconstruction) approach, the sampling is carried } \\
\text { out by taking } 8 \text { samples of LKPD in different curriculum units, namely KTSP and the } \\
2013 \text { curriculum. curriculum), competency aspects, knowledge construction analysis } \\
\text { (first time) and practical analysis. The results show that there are still several } \\
\text { problems in these aspects. In the aspect of relevance, namely the lack of relevance } \\
\text { of LKPD competence and content with KD. In the practical aspect, there are work } \\
\text { procedures and material tools that are not clear so that it can cause errors and there } \\
\text { is no data recording table so that the data that appears is difficult to interpret, there } \\
\text { are problems that are not quite right so that the phenomenon / concept is not } \\
\text { observed. In the aspect of knowledge construction, such as objects / phenomena that } \\
\text { are not in accordance with the focus question and transforming data is not in } \\
\text { accordance with the main activity. Based on the problems found, LKPD } \\
\text { reconstruction was carried out in the bone practicum by taking into account these four } \\
\text { aspects. }\end{array}$ \\
\hline & Key words: Student Worksheets, Laboratory Activities Analysis, 21st century craft \\
\hline Penerbit & ABSTRAK \\
\hline $\begin{array}{l}\text { Program Studi Pendidikan Biologi } \\
\text { FKIP Universitas Jambi, } \\
\text { Jambi- Indonesia }\end{array}$ & $\begin{array}{l}\text { Lembar Kerja Peserta Didik (LKPD) pada pembelajaran Biologi khususnya materi } \\
\text { tulang yang ada dilapangan saat ini belum optimal. Hal ini dapat dilihat dari isi LKPD } \\
\text { yang tidak mencakup semua kompetensi sesuai dengan yang telah dirumuskan } \\
\text { dalam kurikulum. Penelitian ini bertujuan untuk merekonstruksi LKPD pada materi } \\
\text { tulang. Metode penelitian berupa deskriptif kualitatif dengan menggunakan tahapan } \\
\text { ANCOR (Analisis-Coba-Rekonstruksi), pengambilan sampel dilakukan dengan } \\
\text { mengambil } 8 \text { sampel LKPD pada satuan kurikulum yang berbeda yaitu KTSP dan } \\
\text { kurikulum 2013. Instrumen yang digunakan dalam penelitian ini adalah rubrik analisis } \\
\text { aspek relevansi (kegiatan dan kurikulum), aspek kompetensi, analisis konstruksi } \\
\text { pengetahuan (diadaptasi dari novak gowin) dan analisis praktikal. Hasil temuan } \\
\text { menunjukan bahwa masih terdapat beberapa permasalahan pada aspek-aspek } \\
\text { tersebut. Pada aspek relevansi yaitu kurang relevannya kompetensi dan konten } \\
\text { LKPD dengan KD. Pada aspek praktikal adanya prosedur kerja dan alat bahan yang } \\
\text { belum jelas sehingga dapat menimbulkan kesalahan serta tidak adanya tabel } \\
\text { perekaman data sehingga data yang mucnul sulit untuk dinterpretasikan, terdapat } \\
\text { permaslahan waktu yang kurang tepat sehingga fenomena/konsep tidak teramati. } \\
\text { Pada aspek konstruksi pengetahuan seperti objek/fenomena tidak sesuai dengan } \\
\text { pertanyaan fokus dan transformasi data tidak sesuai dengan kegiatan utama. }\end{array}$ \\
\hline
\end{tabular}


Berdasarkan dari permasalahan yang ditemukan, dilakukan rekonstruksi LKPD pada praktikum tulang dengan memeprhatikan ke-empat aspek yaitu aspek relevansi (kegiatan dan kurikulum), aspek kompetensi, analisis konstruksi pengetahuan (diadaptasi dari novak gowin) dan analisis praktikal.

Kata kunci: LKPD, Analisis LKPD, Ketrampilan abad 21

\section{(i) (2) \\ BY No SA}

This BIODIK : Jurnal IImiah Pendidikan Biologi is licensed under a CC BY-NC-SA (Creative Commons Attribution-ShareAlike 4.0 International License)

\section{PENDAHULUAN}

Semakin berkembangnya dunia pendidikan global pada abad ini mendorong banyak perubahan yang harus dibimbing oleh negara kita. Menurut Witt dan Orvis (dalam Eng, 2017) menjelaskan bahwa pendidikan pada abad 21 harus dapat menghasilkan lulusan global yang mempunyai kemampuan, pengetahuan dan motivasi untuk menangani berbagai permaslahan yang ada dilingkungan serta mampu saling menghormati dan terbuka dalam berdiskusi. Ismail (2020) menjelaskan bahwa sistem pendidikan memerlukan suatu perencanaan yang strategis untuk meningkatkan praktiknya dengan kemampuan terbaik untuk memenuhi ketramilan abad 21.

Kemajuan ilmu pengetahuan dan teknologi yang sangat cepat di era 4.0 saat ini menuntut pendidikan untuk meluluskan peserta didik yang memiliki ketrampilan dan sikap individu abad 21 . Menurut Eng (2017) menjelaskan bahwa pelaksanaan pendidikan abad 21 dikenal dengan istilah 6C (Critical thinking, Collaboration, Communication, Creativity, Citizenship, Character). Untuk mejawab tantangan abad 21, dalam proses pembelajaran biologi harus melibatkan interaksi langsung peserta didik dengan hal-hal konkrit suatu fenomena. Hasil penelitian yang dilakukan Makhrus et al (2018), menemukan fakta masih banyak pengajar/guru yang menyusun LKPD tidak sesuai dengan pembelajaran abad 21 dan kurikulum 2013. Rustaman (2017), kegiatan pembelajaran (science aktivities) peserta didik harus dibekali dengan kegiatan untuk mengembangkan operasi mereka menjadi suatu yang bermakna sekaligus melatih keterampilan saintifik peserta didik. Chairani (2016) menjelaskan bahwa pengalaman langsung dapat mengasah ketrampilan meneliti yang mencakup berfikir kritis, penyelesaian masalah dan ingatan jangka panjang sangat dibutuhkan oleh peserta didik. Menurut Millar dalam Harsawati et al.,(2020) bahwa kegiatan praktik merupakan aktifitas belajar dan mengajar yang melibatkan peserta didik ketika observasi, memanipulasi dan menggunakan bahan yang nyata. Keterlibatan peserta didik dengan hal konkrit suatu fenomena dapat ditemukan melalui kegiatan praktikum. Hasil penelitian Yeni (2017) menjelaskan bahwa proses pembelajaran biologi akan lebih bermakna apabila peserta didik terlibat aktif secara intelektual, manual dan sosial, ketrampilan proses sains sebagai proses dan produk perlu dikembangkan melalui pengalaman secara langsung, sebagai pengalaman belajar dan disadari oleh peserta didik ketika kegiatan sedang berlangsung.

Supriatno (2018) menyatakan bahwa sebuah kegiatan praktikum akan lebih banyak memberikan kesempatan kepada peserta didik untuk lebih aktif dalam memperoleh pengetahuan baru melalui data berdasarkan observasi yang dilakukannya dan atau dapat memanipulasi sehingga akan terjadi sebuah proses kontruksi berdasarkan informasi yang faktual. 
Dari hal ini, penting bagi seorang pengajar untuk dapat menyelaraskan setiap kegiatan yang akan dilakukan oleh peserta didik agar sesuai dengan tujuan pembelajaran atau kompetensi yang harus dicapainya. Agar sebuah kegiatan praktikum dapat terlaksana dengan baik dan sistematis, perlu adanya sebuah pedoman yang dapat mengarahkan peserta didik dalam mengkonstruksi pengetahuannya yang berdasarkan temuan dari fenomena atau fakta yang terjadi pada proses praktikum. Supriatno (dalam Harsawati, 2020), memaparkan sebuah permasalahan tentang lembar kerja siswa (LKS) yang banyak beredar dilapangan, yaitu (1) tujuan praktikum lebih banyak menekankan pada aspek kognitif dibanding dengan aspek psikootrii; (2) sebagian besar masih menggunakan pendekatan deduktif dengan model ekspositori; (3) pemilihan materi tidak mempertimbangan esensi keseuaian, kedalaman dan kompleksitasnya; serta (4) pada prosedur kegiatan praktikum, meskipun rinci beberapa diantaranya tidak terstruktur dan perintahnya membingungkan sehingga akan menimbulkan penafsiran ganda atau berbeda. Selain itu adanya permasalahan lain yang menyebabkan peserta didik kesulitan dalam melaksanakan praktikum yaitu masih kurangnya pemahaman yang dimiliki oleh peserta didik mengenai alat dan bahan serta dalam penggunaannya. Sofyan (2016), menyatakan permasalahan lain yang dihadapi oleh peserta didik adalah dalam membuat laporan hasil praktikum yaitu dalam membuat pembahasan, menjawab pertanyaan dan membuat kesimpulan.

Permaslahan lain yang ditemukan oleh Wahidah (2018) dalam penelitiannya bahwa LKPD yang dianalisis masih terdapat kesalahan pada prosedur dan tidak terstruktur. Selain itu, tingkat kognitif yang dituntut dalam LKPD umumnya di dominasi pada pengetahuan C3 yang lebih sesuai dengan tuntutan Kompetensi Dasar SMP. Hal ini karena LKPD yang berada dilapangan tidak diadaptasi sesuai dengan levelnya atau tidak dikonstruksi saat terjadi adanya kesalahan. Menurut Wahidah (2018), diagram vee dapat membantu para pengajar dalam membuat LKPD agar kehiatan praktikum akan menjadi lebih bermakna. Diagram vee akan membantu dalam menemukan makna bahwa pengetahuan berasal dari objek permasalahan yang diamati oleh peserta didik.

Pada kurikulum tingkat SMA/MA yang berlaku di Indonesia saat ini, materi sistem gerak dituntut juga untuk diajarkan melalui proses praktikum untuk mencapai kompetensi yang ingin dicapai. Dengan demikian, dari permasalahan yang telah dipaparkan diatas bahwa perlu adanya analisis LKPD pada materi sistem gerak yang sudah ada kemudian melakukan sebuah rekonstruksi LKPD agar lebih representatif dan lebih efektif sebagai sains activity yang sesuai dengan kompetensi dasar serta kemampuan hasil pengamatan dalam aspek mengkonstruksi pengetahuan yang lebih baik.

\section{METODE PENELITIAN}

Metode yang digunakan dalam penelitian ini adalah deskriftif kualitatif dengan tujuan untuk menggambarkan suatu fenomena desain praktikum SMA Kelas XI yang ditemukan dilapangan secara lebih mendalam dan jelas mengenai praktikum konsep tulang. Penelitian ini mengikuti langkah yang dikembangkan oleh (Supriatno dalam Harsawati, 2020) dengan tahapan ANCOR (Analisis-CobaRekonstruksi). Sampel yang dianalisis adalah LKPD yang terdapat dalam buku paket pada kurikulum KTSP dan Kurikulum 2013 sebanyak 8 LKPD, diantaranya 3 LKPD dari kurikulum KTSP dan 5 LKPD kurikulum 2013 yang terdapat di perpustakaan sekolah SMAN 1 Pabuaran Subang. Teknik sampling yang dilakukan secara purposive sampling. Instrumen yang digunakan adalah instrumen aspek relevansi (kegiatan dan kurikulum), aspek kompetensi (Hands on dan Minds on), aspek analisis konstruksi pengetahuan (diadaptasi dari Novak \& Gowin dalam Harsawati 2020), dan aspek analisis 
praktikal. Analisis data dilakuakan dengan pemberian skor pada LKPD dengan menggunakan rubrik penilaian yang diadaptasi dari rubrik diagram vee dan komponen kurikulum. Hasil analisis berupa kegiatan untuk mengembangkan desain LKPD yang ditinjau dari analisis konseptual, analisis kompetensi, analisis konstruksi pengetahuan berdasarkan diagram vee dan analisis praktikal.

\section{HASIL PENELITIAN DAN PEMBAHASAN}

Hasil analisis kedelapan LKPD yang terdiri dari 5 LKPD Kurikulum 2013 dengan kompetensi dasar 3.5 Menganalisis hubungan antara struktur jaringan penyusun organ pada sistem gerak dalam kaitannya dengan bioproses dan gangguan fungsi yang dapat terjadi pada sistem gerak manusia. 4.5 Menyajikan karya tentang pemanfaatan teknologi dalam mengatasi gangguan sistem gerak melalui studi literatur. dan 3 LKPD dari kurikulum KTSP dengan kompetensi dasar 3.1 menjelaskan karakteristik antara struktur, fungsi, dan proses serta kelainan/penyakit yang dapat terjadi pada sistem gerak pada manusia.

\section{Analisis Konseptual LKPD Struktur Tulang}

Data hasil analisis konseptual kedelapan LKPD yang meliputi relevansi kompetensi dengan KD dan relevansi konten dengan KD dapat dilihat pada tabel 1.

Tabel 1. Hasil Analisis Aspek Konseptual

\begin{tabular}{|c|c|c|c|c|c|c|c|c|c|c|}
\hline Indikator & $\begin{array}{c}\text { LKPD } \\
1\end{array}$ & $\begin{array}{c}\text { LKPD } \\
2\end{array}$ & $\begin{array}{c}\text { LKPD } \\
3\end{array}$ & $\begin{array}{c}\text { LKPD } \\
4\end{array}$ & $\begin{array}{c}\text { LKPD } \\
5\end{array}$ & $\begin{array}{c}\text { LKPD } \\
6\end{array}$ & $\begin{array}{c}\text { LKPD } \\
7\end{array}$ & $\begin{array}{c}\text { LKPD } \\
8\end{array}$ & $\begin{array}{l}\text { Rata } \\
\text {-rata }\end{array}$ & Presentase \\
\hline $\begin{array}{l}\text { Relevansi } \\
\text { Kompeten } \\
\text { si dengan } \\
\text { KD }\end{array}$ & 1 & 1 & 1 & 1 & 1 & $1^{a}$ & $1^{a}$ & $0^{a}$ & 0,75 & $\begin{array}{l}\text { Skor } 0=0 \% \\
\text { Skor } 1=87,5 \% \\
\text { Skor } 2=2,5 \%\end{array}$ \\
\hline $\begin{array}{l}\text { Relevansi } \\
\text { Konten } \\
\text { dengan KD }\end{array}$ & 1 & 1 & 1 & 1 & 1 & $1^{a}$ & $1^{a}$ & $0^{a}$ & 0,75 & $\begin{array}{l}\text { Skor } 0=0 \% \\
\text { Skor } 1=87,5 \% \\
\text { Skor } 2=2,5 \%\end{array}$ \\
\hline Total Skor & 2 & 2 & 2 & 2 & 2 & 2 & 2 & 0 & 0,75 & \\
\hline
\end{tabular}

a Kurikulum KTSP

Pada tebel 1. Menunjukan adanya temuan dari hasil analisis konseptual pada setiap indikator memiliki skor yang sama dengan nilai rata-rata 0,75 , artinya bahwa pada aspek konseptual relevansi kompetensi dengan KD dan relevansi konten dengan KD pada kegiatan praktikum struktur tulang sudah memenuhi nilai standar minimal kompetensi dasar pada kurikulum. Hanya terdapat satu LKPD dari kurikulum KTSP yang tidak memenuhi standar minimal KD pada relevansi kompetensi dan konten dengan KD yang dikembangkan pada kegiatan praktikum.

\section{Analisis Kompetensi}

LKPD yang dianalisis memiliki skor yang sangat bervariasi, namun belum menunjukan adanya komponen kompetensi. Masih banyak LKPD yang dianalisis belum memiliki adanya kegiatan transformasi data dan kegiatan praktikum hanya melibatkan pada kemampuan berfikir level rendah. Hasil analsis pada aspek kompetensi ditunjukan pada tabel 2. 
Tabel 2. Hasil Analisis Aspek Kompetensi

\begin{tabular}{|c|c|c|c|c|c|c|c|c|c|c|}
\hline Indikator & $\begin{array}{c}\text { LKPD } \\
1\end{array}$ & $\begin{array}{l}\text { LKPD } \\
2\end{array}$ & $\begin{array}{c}\text { LKPD } \\
3\end{array}$ & $\begin{array}{l}\text { LKPD } \\
4\end{array}$ & $\begin{array}{l}\text { LKPD } \\
5\end{array}$ & $\begin{array}{c}\text { LKPD } \\
6\end{array}$ & $\begin{array}{c}\text { LKPD } \\
7\end{array}$ & $\begin{array}{l}\text { LKPD } \\
8\end{array}$ & $\begin{array}{l}\text { Rata- } \\
\text { rata }\end{array}$ & Presentase \\
\hline $\begin{array}{l}\text { Kemampu } \\
\text { an } \\
\text { observasi }\end{array}$ & 1 & 2 & 1 & 1 & 2 & $2^{a}$ & $1^{a}$ & $1^{a}$ & 1,37 & $\begin{array}{l}\text { Skor } 0=0 \% \\
\text { Skor } 1=62,5 \% \\
\text { Skor } 2=37,5 \%\end{array}$ \\
\hline $\begin{array}{l}\text { Transform } \\
\text { asi data }\end{array}$ & 1 & 1 & 0 & 1 & 1 & $1^{a}$ & $0^{a}$ & $0^{a}$ & 0,62 & $\begin{array}{l}\text { Skor } 0=62,5 \% \\
\text { Skor } 1=62,5 \% \\
\text { Skor } 2=0 \%\end{array}$ \\
\hline $\begin{array}{l}\text { Interpreta } \\
\text { si }\end{array}$ & 1 & 1 & 0 & 1 & 1 & $1^{a}$ & $0^{a}$ & $0^{a}$ & 0,62 & $\begin{array}{l}\text { Skor } 0=62,5 \% \\
\text { Skor } 1=62,5 \% \\
\text { Skor } 2=0 \%\end{array}$ \\
\hline $\begin{array}{l}\text { Level } \\
\text { kemampu } \\
\text { an tingkat } \\
\text { tinggi }\end{array}$ & 0 & 2 & 0 & 0 & 1 & $1^{a}$ & $1^{a}$ & $0^{a}$ & 0,62 & $\begin{array}{l}\text { Skor } 0=50 \% \\
\text { Skor } 1=37,5 \% \\
\text { Skor } 2=12,5 \%\end{array}$ \\
\hline Total Skor & 3 & 6 & 1 & 3 & 5 & 5 & 2 & 1 & & \\
\hline
\end{tabular}

${ }^{a}$ Kurikulum KTSP

Tabel 2. Hasil analisis kompetensi menunjukan pada kemampuan observasi mendapat skor ratarata 1,37, artinya LKPD hanya mengobservasi karakter umum dari suatu objek atau fenomena saja. Adapun pada indikator transformasi data hanya mendapat skor rata-rata 0,62 itu artinya bahwa masih terdapat banyak data kualitatif atau kuantitatif yang dipresentasikan dalam bentuk standar, peserta didik belum diarahkan untuk mentransformasikan data hasil pengamatannya kedalam bentuk lain dengan tepat dan membantu dalam proses menginterpretasi data. Begitupun pada indikator interpretasi data, hasil analisis LKPD, interpretasi data hanya membaca komponen data saja. Peserta didik tidak diarahkan dalam menggambarkan hubungan yang diperlihatkan oleh grafik dan mengidentifikasi pengetahuan lain yang mendukung untuk menginterpretasi data. Pada indikator level pengetahuan berfikir tingkat tinggi, mendapat skor rata-rata 0,62, hal ini disebabkan hanya ada satu LKPD yang kegiatan praktikumnya telah didesain untuk mengembangkan kemampuan berfikir tinggi pada level mengevaluasi (C5), dan empat LKPD masih didesain hanya melibatkan kemampuan berfikir level LOTS.

\section{Analisis Konstruksi Pengetahuan}

Rekonstruksi pengetahaun pada LKPD berupa butir-butir pertanyaan yang sifanya mengkonstruk pemahaman konsep. Pada LKPD yang dianalisis memiliki butir pertanyaan yang beragam baik dari jumlah dan esensi pertanyan. Terdapat beberapa yang mengkonstruk pemahaman peserta didik dan beberapa ada yang tidak.

Tabel 3. Hasil Analisis Aspek Konstruksi Pengetahuan

\begin{tabular}{|c|c|c|c|c|c|c|c|c|c|c|}
\hline Indikator & $\begin{array}{l}\text { LKPD } \\
1\end{array}$ & $\begin{array}{l}\text { LKPD } \\
2\end{array}$ & $\begin{array}{l}\text { LKPD } \\
3\end{array}$ & $\begin{array}{l}\text { LKPD } \\
4\end{array}$ & $\begin{array}{l}\text { LKPD } \\
5\end{array}$ & $\begin{array}{l}\text { LKPD } \\
6\end{array}$ & $\begin{array}{l}\text { LKPD } \\
7\end{array}$ & $\begin{array}{l}\text { LKPD } \\
8\end{array}$ & $\begin{array}{l}\text { Rata- } \\
\text { rata }\end{array}$ & Presentase \\
\hline $\begin{array}{l}\text { Judul/Tujuan/ } \\
\text { Pertanyaan } \\
\text { Fokus }\end{array}$ & 3 & 3 & 2 & 1 & 3 & $3^{a}$ & $2^{a}$ & $1^{a}$ & 2,25 & $\begin{array}{l}\text { Skor } 0=0 \% \\
\text { Skor 1 }=25 \% \\
\text { Skor 2 }=25 \% \\
\text { Skor 3 }=50 \%\end{array}$ \\
\hline $\begin{array}{l}\text { Objek } \\
\text { fenomena }\end{array}$ & 1 & 2 & 1 & 1 & 2 & $2^{a}$ & $1^{a}$ & $1^{a}$ & 1,37 & $\begin{array}{l}\text { Skor } 0=0 \% \\
\text { Skor 1 }=62,5 \% \\
\text { Skor 2 }=37,5 \% \\
\text { Skor 3 }=0 \%\end{array}$ \\
\hline $\begin{array}{l}\text { Teori, Prinsip } \\
\text { dan Konsep }\end{array}$ & 3 & 4 & 2 & 2 & 4 & $4^{a}$ & $2^{a}$ & $2^{a}$ & 2,87 & $\begin{array}{l}\text { Skor } 0=0 \% \\
\text { Skor } 1=0 \% \\
\text { Skor } 2=50 \%\end{array}$ \\
\hline
\end{tabular}




\begin{tabular}{|c|c|c|c|c|c|c|c|c|c|c|}
\hline & & & & & & & & & & $\begin{array}{l}\text { Skor } 3=12,5 \% \\
\text { Skor } 4=37,5 \%\end{array}$ \\
\hline $\begin{array}{l}\text { Perekaman } \\
\text { dan } \\
\text { transformasi } \\
\text { data }\end{array}$ & 2 & 3 & 3 & 3 & 3 & $3^{a}$ & $1^{a}$ & $0^{\mathrm{a}}$ & 2,25 & $\begin{array}{l}\text { Skor } 0=12,5 \% \\
\text { Skor } 1=12,5 \% \\
\text { Skor } 2=12,5 \% \\
\text { Skor } 3=62,5 \% \\
\text { Skor } 4=0 \%\end{array}$ \\
\hline $\begin{array}{l}\text { Perolehan } \\
\text { pengetahuan }\end{array}$ & 2 & 3 & 3 & 3 & 3 & $3^{a}$ & $2^{a}$ & $2^{a}$ & 2.62 & $\begin{array}{l}\text { Skor } 0=0 \% \\
\text { Skor } 1=0 \% \\
\text { Skor 2 }=37,5 \% \\
\text { Skor } 3=62,5 \% \\
\text { Skor } 4=0 \%\end{array}$ \\
\hline Total Skor & 11 & 15 & 11 & 10 & 15 & 15 & 7 & 6 & & \\
\hline
\end{tabular}

${ }^{\mathrm{a}}$ Kurikulum KTSP

Hasil temuan pada komponen konstruksi pengetahuan (tabel 3). Pada umumnya sudah menunjukan adanya komponen diagram Vee. Tetapi skor yang didapat masih sangat bervariasi. Hanya ada tiga LKPD yang hampir sempurna memiliki seluruh komponen diagram Vee. Sedangkan LKPD lainnya yang muncul hanya judul/tujuanpertanyaan fokus mendapat skor 2,25 yang artinya belum memfokuskan pada hal utama yang berkaitan dengan objek dan peristiwa dan tidak mengandung bagian konseptual terutama prinsip. Indikator teori, prinsip dan konsep mendapatkan nilai rata-rata tertinggi yaitu 2,87 pada beberapa LKPD sudah didesain untuk memunculkan konsep dan prinsip serta teori yang relevan teridentifikasi. Pada indikator perekaman dan transformasi data mendapat skor 2,25 yang artinya bahwa kegiatan pencatatan dapat diidentifikasi dan sesuai dengan peristiwa utama, transformasi data beberapa tidak konsisten dengan pertanyaan fokus.

Skor rata-rata terendah didapat pada indikator objek fenomena. Hal ini berhubungan dengan hasil uji coba LKPD yang tidak mampu menunjukan objek/fenomena setelah melakukan praktikum. Ketidakmunculan suatu objek dalam kegiatan praktikum akan sangat mempengaruhi nilai dari komponen konsep/prinsip.teori, transformasi dan klaim pengetahuan. Supriatno (2018) menjelaskan bahwa bila suatu objek yang diobservasi tidak dapat dipahami oleh peserta didik, maka bentuk catatan maupun transformasinya akan memperlihatkan suatu konsep yang tidak tepat dan prinsip yang terbentuk salah dan pada akhirnya akan membentuk klaim pengetahuan yang salah.

\section{Analisis Praktikal}

Hasil analisis ke delapan LKPD menunjukan skor yang bervariasi, terdapat beberpa LKPD yang hampir mencapai skor sempurna.

\begin{tabular}{|c|c|c|c|c|c|c|c|c|c|c|}
\hline Indikator & $\begin{array}{l}\text { LKP } \\
\text { D } 1\end{array}$ & $\begin{array}{c}\text { LKPD } \\
2\end{array}$ & $\begin{array}{c}\text { LKPD } \\
3\end{array}$ & $\begin{array}{c}\text { LKPD } \\
4\end{array}$ & $\begin{array}{l}\text { LKPD } \\
5\end{array}$ & $\begin{array}{c}\text { LKPD } \\
6\end{array}$ & $\begin{array}{c}\text { LKPD } \\
7\end{array}$ & $\begin{array}{c}\text { LKPD } \\
8\end{array}$ & $\begin{array}{c}\text { Rata- } \\
\text { rata }\end{array}$ & Presentase \\
\hline $\begin{array}{l}\text { Alat dan } \\
\text { bahan sesuai } \\
\text { dengan } \\
\text { standar } \\
\text { sekolah dan } \\
\text { mudah } \\
\text { didapatkan }\end{array}$ & 3 & 1 & 2 & 3 & 3 & $3^{a}$ & $1^{a}$ & $1^{a}$ & 2,12 & $\begin{array}{l}\text { Skor } 0=0 \% \\
\text { Skor 1 }=37,5 \% \\
\text { Skor 2 }=12,5 \% \\
\text { Skor 3 }=50 \%\end{array}$ \\
\hline $\begin{array}{l}\text { Alat dan } \\
\text { bahan } \\
\text { memiliki } \\
\text { satuan yang }\end{array}$ & 2 & 2 & 2 & 2 & 3 & $3^{a}$ & $1^{\mathrm{a}}$ & $1^{a}$ & 2 & $\begin{array}{l}\text { Skor } 0=0 \% \\
\text { Skor } 1=25 \% \\
\text { Skor 2 }=50 \% \\
\text { Skor 3 }=25 \%\end{array}$ \\
\hline
\end{tabular}

\section{As Syiba, dkk}




\begin{tabular}{|c|c|c|c|c|c|c|c|c|c|c|}
\hline jelas & & & & & & & & & & \\
\hline $\begin{array}{l}\text { Prosedur } \\
\text { kerja } \\
\text { terstruktur } \\
\text { dan tidak } \\
\text { menimbulkan } \\
\text { kesalahan }\end{array}$ & 2 & 2 & 1 & 2 & 2 & $2^{a}$ & $1^{a}$ & $1^{a}$ & 1,62 & $\begin{array}{l}\text { Skor } 0=0 \% \\
\text { Skor 1 }=37,5 \% \\
\text { Skor 2 }=62,5 \% \\
\text { Skor 3 }=0 \%\end{array}$ \\
\hline $\begin{array}{l}\text { Objek } \\
\text { fenomena } \\
\text { muncul dan } \\
\text { mudah } \\
\text { diamati } \\
\text { melalui } \\
\text { prosedur } \\
\text { kerja }\end{array}$ & 3 & 3 & 3 & 3 & 3 & $3^{a}$ & $1^{a}$ & $1^{a}$ & 2,5 & $\begin{array}{l}\text { Skor } 0=0 \% \\
\text { Skor 1 }=25 \% \\
\text { Skor 2 }=0 \% \\
\text { Skor 3 }=75 \%\end{array}$ \\
\hline $\begin{array}{l}\text { Tabel } \\
\text { perekaman } \\
\text { data sesuai } \\
\text { dengan objek } \\
\text { fenomena } \\
\text { yang muncul } \\
\text { dan mudah di } \\
\text { interpretasi }\end{array}$ & 3 & 3 & 3 & 3 & 3 & $3^{a}$ & $1^{a}$ & $1^{a}$ & 2,5 & $\begin{array}{l}\text { Skor } 0=0 \% \\
\text { Skor 1 }=25 \% \\
\text { Skor 2 }=0 \% \\
\text { Skor 3 }=75 \%\end{array}$ \\
\hline
\end{tabular}

Tabel 4. Menunjukah bahwa data hasil LKPD yang ada sudah menunjukan komponen praktikal, dan skor yang didapat sangat bervariasi. Pada indikator alat dan bahan didapatkan $50 \%$ LKPD sudah sesuai dengan standar laboratorium sekolah dan mudah didapatkan. Pada indikator yang kedua, terdapat 4 LKPD yang belum menuliskan alat dan bahan secara jelas, namun ada 2 LKPD yang sudah menuliskan semua alat dan bahan mempunyai satuan yang jelas sehingga proses praktikum lebih terarah atau mudah untuk dilakukan. Indikator ke tiga yaitu prosedur kerja terstruktur dan tidak menimbulkan kesalahan memiliki skor rata-rata 1,62 artinya bahwa pada LKPD yang dianalisis memiliki prosedur kerja yang jelas, namun tidak dilengkapi dengan adanya gambar/ilustrasi/bagan dan tidak menimbulkan kesalahan. Namun terdapat 2 LKPD yang masih belum memiliki prosedur kerja yang jelas dan dapat menimbulkan kesalahan.

Pada indikator keempat yaitu objek dan fenomena muncul dan mudah diamati melalui prosedur kerja didapatkan sekor rata-rata 2,5 artinya bahwa hampir semua LKPD sudah dapat menunjukan objek dan fenomena dapat teramati melalui seluruh langkah prosedur kerja, namun masih terdapat ketidaksesuaian dengan alokasi waktu yang sudah ditentukan pada LKPD. Karena pada praktikum ini membutuhkan waktu yang lama untuk memunculkan fakta dan fenomena secara utuh. Begitupun pada indikator tabel perekaman data, didapatkan hasil rata-rata 2,5 yang artinya bahwa tabel perekaman data sesuai dan dapat merekam seluruh objek dan fenomena yang terjadi dalam proses praktikum. Terdapat beberapa LKPD yang tidak menyajikan adanya tabel sebagai perekaman data sehingga tidak dapat menginterpretasikan data.

\section{Rekonstruksi LKPD Struktur Tulang}

Berdasarkan atas permasalahan yang ditemukan pada analisis keidealan LKPD, dibuatlah rekonstruksi LKPD berbasis ketrampilan abad 21 dengan menyesuaikan KD pada kurikulum 2013, tingkat kognitif peserta didik, keseuaian konten dengan judul/tujuan/pertanyaan fokus praktikum dan 
diharapkan layak untuk digunakan. Millar (dalam Ria 2020) menjelaskan bahwa efektivitas suatu LKPD dapat diukur dari segi prosedur kegiatan dan hasil kerja praktikum. Prosedur kegiatan pada LKPD ini berkaitan dengan apa yang dikerjakan oleh peserta didik untuk mengkonstruksi pengetahuannya dan mengembangkan ketrampilan abad 21. Efektivitas dari segi hasil kerja praktikum yaitu terlaksananya prosedur kerja dalam desain LKPD yang dikembangkan dan juga menghasilkan fakta atau data yang sesuai dengan tujuan pembelajaran. Pencapaian ketrampilan abad 21 ini dapat dilakukan dengan proses pembelajaran praktikum untuk meningkatkan dan mengembangkan partisipasi, medoroang kerjasama dan komunikasi serta membudayakan ketrampilan berfikir kreatif sehingga proses pembelajaran akan berpusat pada kegiatan peserta didik dengan adanya bimbingan dan pengawasan dari pengajar/guru.

Rekonstruksi LKPD juga dikembangkan dengan mengacu pada diagram vee, hal ini disebabkan karena diagram vee dapat membantu seorang pengajar dalam membuat LKPD dengan tujuan agar proses kegiatan praktikum menjadi lebih bermakna. Menurut Wahidah (2018), tidak lengkapnya suatu komponen diagram vee suatu LKPD, seperti tidak adanya objek/peristiwa akan menyebabkan komponen diagram vee tidak muncul atau memiliki skor rendah dengan kata lain bahwa LKPD tidak menunjang dalam proses konstruksi pengetahuan. Sehingga praktikum yang dilaksanakan tidak memberikan dampak terhadap peningkatan pengetahuan peserta didik. Maka peneliti mencoba untuk merekonstruksi LKPD pada praktikum struktur tulang dengan berbasis ketramilan abad 21 .

Permaslahan penting yang ditemukan dari hasil analisis kedelapan LKPD sebagian besar adalah adanya ketidakmunculan fakta yang benar dari hasil kegiatan praktikum. Hal ini dikarenakan kurangnya alokasi waktu yang diperlukan dalam melaksanakan kegiatan praktikum, sebagian besar kegiatan praktikum disekolah menggunakan alokasi waktu pembelajaran dikelas dan tidak memiliki waktu khusus, akan tetapi bagi sebagian besar praktikum dengan waktu yang tersedia tidak mencukupi untuk memunculkan fakta dalam sebuah kegiatan praktikum. Oleh sebab itu penulis mencoba merekonstruksi LKPD dengan mengatur jenis bagian tulang dalam praktikum dan meningkatkan konsentrasi larutan HCL menjadi 25\% karena akan mempengaruhi laju reaksi yang terjadi.

\section{PENTINGNYA KALSIUM UNTUK TULANG}

“Bagaimanakah peran kalsium pada tulang ?”

\section{A. Kompetensi Dasar :}

Menganalisis hubungan antara struktur jaringan penyusun organ pada sistem gerak dalam kaitannya dengan bioproses dan gangguan fungsi yang dapat terjadi pada sistem gerak manusia

B. Tujuan Eksperimen :

setelah melakukan eksperimen ini siswa dapat:

1. Mengidentifikasi peran kalsium pada tulang

2. Menelaah pengaruh larutan HCL pada tulang

3. Menemukan perbedaan struktur antara tulang keras dengan struktur tulang rawan

4. Menganalisis hubungan antara tingkat kelenturan tulang dan akibatnya pada fungsi tulang dengan penurunan jumlah kalsium pada tulang. 


\section{Teori}

Tulang merupakan salah satu jenis jaringan ikat. Tulang memiliki struktur yang unik karena matriksnya padat. Matriks tulang mengandung mineral keras seperti Kalsium dan Posfor. Serabut yang terdapat pada tulang adalah serabut kolagen. Matriks dan serabut inilah menjadikan tulang kaku dan kuat. Jumlah kalsium yang semakin banyak terakumulasi selama masa pertumbuhan, akan semakin kecil pula kemungkinnanya untuk mengalami kelainan pada sistem gerak dimasa yang akan datang.

Sebagian besar kalsium dalam tubuh disimpan dalam tulang. Bahkan, tulang terdiri dari $40 \%$ kalsium. Ketika kadar kalsium dalam darah turun dibawah normal, kalsium diambil dari tulang untuk mengembalikan kadar normal dalam darah. Kehilangan banyak kalsium pada tubuh akan menyebabkan berbagai kelainan seperti osteoporosis suatu kondisi dimana terjadinya penurunan kepadatan tulang yang sering menyebabkan patah tulang.

Berdasarkan zat penyusunnya, tulang dibedakan menjadi tulang keras dan tulang rawan. Tulang rawan tersusun dari sel-sel tulang rawan yang bersifat lentur, ruang antar sel banyak mengandung perekat dan sedikit zat kapur. Sedangkan tulang keras banyak mengandung zat kapur, sedikit zat perekat sehingga bersifat keras. Dalam tulang keras terdapat saluran havers yang didalamnya terdapat pembuluh darah yang berfungsi mengatur kehidupan sel tulang.

Pada kegiatan ini akan menggunakan larutan Asam klorida $(\mathrm{HCL})$, merupakan cairan kimia yang bersifat korosif. Seperti yang kita ketahui bahwa komponen utama tulang adalah unsur Ca (Klasium). $\mathrm{HCL}$ memiliki kecendrungan untuk melarutkan unsur kimia seperi kalsium dengan mengikuti reaksi $\mathrm{HCl}$ $+\mathrm{Ca}-->\mathrm{CaCl} 2+\mathrm{H} 2$.

\section{Alat dan Bahan}

Alat :

1. Gelas Kimia $500 \mathrm{ml}$

2. Sarung tangan lateks

3. Cawan petri

4. Pinset

5. Pisau cutter/Silet

6. Gergaji kecil
Bahan :

1. Larutan $\mathrm{HCL} 25 \%$

2. Tulang paha ayam

3. Tulang dada aayam

\section{E. Langkah Kegiatan}

1. Berhati-hatilah dalam melakukan eksperimen ini.

2. Pakailah sarung tangan sebelum melakukan eksperimen

3. Periksalah kembali perlengkapan alat dan bahan yang akan digunakan

4. Bersihkan tulang dada dan paha ayam dari daging yang telah melekat dengan menggunakan cutter/silet.

5. Amati kekerasan, kelenturan dan warna tulang, lalu tuliskan pada data ekperimen.

6. Potong tulang menggunakan gergaji kecil, amati penampang melintangnya.

7. Siapkan larutan HCL $25 \%$ sebanyak $200 \mathrm{ml}$ dalam gelas kimia

8. Rendam tulang ke dalam larutan selama 2 jam (120 menit).

9. Angkat dan pindahkan tulang ke cawan petri dengan menggunakan pinset.

10. Amati kekerasan, kelenturan, warna dan bagian dalam tulang yang telah direndam dan tuliskan pada tabel data eksperimen. 
F. Data Eksperimen

\begin{tabular}{|l|l|l|l|l|}
\hline \multicolumn{1}{|c|}{ Kriteria } & \multicolumn{2}{c|}{ Kondisi sebelum direndam } & \multicolumn{2}{c|}{ Kondisi setelah direndam } \\
\cline { 2 - 5 } pengamatan & Tulang dada & Tulang paha & Tulang dada & Tulang paha \\
\hline Kekerasan & & & & \\
\hline Kelenturan & & & & \\
\hline $\begin{array}{l}\text { Warna bagian } \\
\text { luar }\end{array}$ & & & & \\
\hline $\begin{array}{l}\text { Warna bagian } \\
\text { dalam }\end{array}$ & & & & \\
\hline
\end{tabular}

\section{G. Tugas dan Pertanyaan}

1. Tuliskan ulasan anda tentang perbandingan setiap kriteria pengamatan pada kondisi sebelum dan sesudah proses perendaman tulang dengan larutan $\mathrm{HCL} 25 \%$ selama 1 jam!

2. Jelaskan fungsi dari pemberian larutan $\mathrm{HCL} 25 \%$ pada eksperimen ini!

3. Berdasarkan hasil eksperimen, apakah peran kalsium pada tulang!

4. Jelaskan pengaruh perendaman tulang pada larutan $\mathrm{HCL} 25 \%$ !

5. Tuliskan perbedaan antara tulang keras dan tulang rawan berdasarkan eksperimen ini!

\begin{tabular}{|c|c|c|c|}
\hline No & Pembeda & Tulang rawan & Tulang keras \\
\hline 1 & & & \\
\hline 2 & & & \\
\hline 3 & & & \\
\hline 4 & & & \\
\hline 5 & & & \\
\hline & & & \\
\hline
\end{tabular}

6. Menurut anda, coba jelaskan apakah tulang rawan dapat berubah menjadi tulang keras?

7. Menurut anda, coba jelaskan apakah tulang keras dapat berubah menjadi tulang rawan?

8. Anda memiliki bobot tubuh yang berat! Menurut anda, apakah tulang yang lentur akan mampu menopang tubuh? Jelaskan, mengapa demikian?

9. Berdasarkan hasil pengamatan pada ekperimen yang anda lakukan, apakah yang terjadi jika tubuh kita kehilangan banyak kalsium dan tidak adanya penambahan kalsium dalam tubuh? Jelaskan! 
10. Berdasarkan hasil pengamatan pada ekperimen yang anda lakukan, apakah yang terjadi jika tubuh kita kehilangan banyak kalsium dan tidak adanya penambahan kalsium dalam tubuh? Jelaskan!

H. Penilaian

Susunlah dalam bentuk laporan dan dipresntasikan di depan teman-teman sekelas anda Kumpulkan laporan hasil eksperimen kepada guru anda.

Tabel. Hasil penilaian

\begin{tabular}{|l|l|l|l|l|l|}
\hline \multirow{2}{*}{ No } & \multirow{2}{*}{ Nama Peserta didik } & \multicolumn{2}{|c|}{ Aspek yang dinilai } & \multirow{2}{*}{ Total Skor } \\
\cline { 3 - 5 } & & Kesungguhan & Kecermatan & Isi Laporan & \\
\hline 1 & & & & & \\
\hline 2 & & & & & \\
\hline 3 & & & & & \\
\hline 4 & & & & & \\
\hline Dst. & & & & \\
\hline
\end{tabular}

I. Format Penulisan Laporan

- Cover

- Pendahuluan : studi pustaka terkait sistem gerak (Tulang)

- Metode pengamatan

- Pembahasan

- Kesimpulan

- Daftar pustaka

Fakta yang ditemukan saat uji coba, bahwa untuk mencapai tulang sampai menjadi lentur tetap membutuhkan waktu lama dan dengan penggunaan larutan $\mathrm{HCL}$ dengan konsentrasi tinggi dapat berbahaya dan harus menggunakan sarung tangan namun masih bisa dilakukan di laboratorium biasa (sekolah). Sehingga peneliti mengatur alokasi waktu dalam praktikum dapat dilakukan diluar jam pelajaran sehingga peserta didik akan menemukan fakta secara utuh untuk mengkonstruksi pengetahuannya.

\section{SIMPULAN}

Hasil analisis kedelapan LKPD praktikum tulang pada kurikulum KTSP dan Kurikulum 2013 memiliki konten dan tingkat kognitif yang belum sesuai dengan tuntutan kompetensi, seperti belum memiliki adanya kegiatan transformasi data dan kegiatan praktikum hanya melibatkan pada kemampuan berfikir level rendah. Pada konstruksi pengetahuan tidak adanya pertanyaan fokus sehingga belum memunculkan objek fenomena. Ketidakmunculan suatu objek dalam kegiatan praktikum akan sangat mempengaruhi nilai dari komponen konsep/prinsip/teori, transformasi dan klaim pengetahuan, bila suatu objek yang diobservasi tidak dapat dipahami oleh peserta didik, maka bentuk catatan maupun transformasinya akan memperlihatkan suatu konsep yang tidak tepat dan prinsip yang terbentuk salah, dan pada akhirnya akan membentuk klaim pengetahuan yang salah. Artinya bahwa pada beberapa LKPD yang dianalisis masih belum mampu mengkonstruksi konsep, prinsip dan teori 
berdasarkan fakta yang terbentuk. LKPD praktikum tulang masih memerlukan perbaikan dari aspek konseptual, prosedural dan konstruksi pengetahuan untuk mencapai kompetensi yang diharapkan dalam kegiatan praktikum.

\section{UCAPAN TERIMA KASIH}

Ucapan terimakasih penulis sampaikan kepada Bapak Dr. Bambang Supriatno, M.Si, Ibu Dr. Sri Anggraeni selaku dosen pembimbing yang telah memberikan arahan, dukungan, motivasi dan nasihat kepada penulis. Terimakasih penulis ucapkan kepada Bapak Dr. Bambang Nugroho selaku Kepala Sekolah SMA N 1 Pabuaran Subang. Dan kepada siswa-siswi SMAN 1 Pabuaran Subang.

\section{RUJUKAN}

Anita,R.E., Supriatno, B.,\& Anggraeni, S (2020). Rekonstruksi dan Pengem,bangan Lembar Kerja Siswa pada Materi Plantae Submateri Spermatophyta dengan Pendekatan Keterampilan Proses. $6,507-518$.

Eng, James A.J (Eds 2017). Panduan Pelaksanaan Abad Ke-21: Kehendak Pendidikan Abad Ke-21. 2017. Malaysia: Institut Aminuddin Baki Kementrian Pendidikan Malaysia.

Harsawati, F., Anggraeni, S.,\& Supriatno, B (2020). Analisis Lembar Kerja Siswa Pada Praktikum Biologi SMA Pada Materi Uji Kandungan Zat Makanan (Analysis of student Worksheets of Biology Practikum in High School on Subject Matter Test Food Content ) 6, 570-583. https://doi.org/10.22437/bio.v614.9456

Ismail, N.A., Wahid, N.A., Yusoff, A. S. M.,Wahab, N. a., Rahim, B. H. A., Majid, N. A,. Din, N. M. N,. Arifin, R., Adnan, W. I, W., \& Zakaria, A. R. (2020). The Challenges of Industrial Revolution (IR) 4.0 towards the Teacher's Self-Efficacy. Journal of Physics: Conference Series, 1529(4), 0-6/ https://doi.org/10.1088/1742-6596/1529/4/042062.

Makhrus, Muh,. dkk. (2018). Identifikasi Kesiapan LKPD Guru Terhadap Ketrampilan Abad 21 Pada Pembelajaran IPA SMP.Jurnal IImiah Profesi Pendidikan. Vol 3, No 2. 124-128.

Millar, R. (2004). The role of practical work in the teaching and learning of science.

Wachington DC: National Academy of Sciences.

Rustaman, N. Y. (2017). Mewujudkan sistem pembelajaran sains / biologi berorientasi pengembangan literasi peserta didik. Biologi, Pembelajaran, Dan Lingkungan Hidup Perspektif Interdisipliner, April, 1-8. http://researchreport.umm.ac.id/index.php.

Shanty, Chairani. (2016). Peningkatan Minat Belajar Peserta Didik Melalui Metode Praktikum pada Materi Metabolisme Di SMAN 3 Tangerang Selatan. November, 593-607

Sinambela, Perdomuan N.J.M, (2013). Kurikulum 2013 dan Implementasinya dalam Pembelajaran. Jurnal Generasi Kampus, UNIMED. Vol 6, No 2

Sofyan, Herminarto. (2016). Penyusunan Panduan Praktikum. Applied Approach Buku 2. UNY Press: Yogyakarta.

Supriatno, B. (2018). Praktikum untuk Membangun Kompetensi. Proceeding Biologi Education Conference, 15 (1), 1-18. 
Supriatno, B. (2013). Pengembangan program perkuliahan pengembangan praktikum biologi sekolah berbasis ANCORB untuk mengembangkan kemampuan merancang dan mengembangkan desain kegiatan laboratorium. In Universitas Pendidikan Indonesia. Universitas Pendidikan Indonesia.

Suryaningsih, Yeni (2017). Pembelajaran Berbawsis Praktikum Sebagai Sarana Siswa untuk Berlatih Menerapkan Ketrampilan Proses Sains dalam Materi Biologi. Jurnal Bio Educatio. Vol 2. No. 2. 49-57.

Wahidah, N. S., Supriatno, B., \& Kusumastuti, M. N. (2018). Analisis Struktur dan Kemunculan Tingkat Kognitif pada Desain Kegiatan Laboratorium Materi Fotosintesis. Indonesian Journal of Biology Education, 1(2), 70-76. https://doi.org/https://doi.org/10.17509/aijbe.v1i2.13050.

Zubaidah, (2018). Mengenal 4C: Learning And Innovation Skills Untuk Menghadapi Era Revolusi Industri 4.0. 2nd Science Education National Conference, 1-7. 